Species Martiana secundum auctores campestris est. - Warming (l. c.. p. 93) commemorat arborem ad fluvios civitatis Goyaz a Pohl lectam, quae forsan ad speciem supra descriptam pertineat.

\title{
LX. Rob. E. Fries, Anonaceae Regnellianae atque Riedelianae Austro-americanae novae.
}

(Aus: Arkiv för Botanik, IV, no. 19 [1905] und $r$, no. 4 [1905].)

1. Aberemoa brevipedunculata R. E. Fries, I. c., IV, no. 19, p. 8, tab. 1 . fig. 10 .

Arbor parva; ramulis, foliis subtus, pedunculis, calyce et petalis extus dense lepidotis et fulvo-argenteis; foliis breviter sed distincte petiolatis, lanceolatis, basi contractis vel subrotundis, apice acutis, coriaceis, supra etiam novellis glaberrimis et nitidis; floribus majusculis, pedunculis suboppositifoliis, brevissimis et bibracteatis suffultis; sepalis ovatis, acutis; petalis calycem subduplo superantibus, ovatis vel ovato-oblongis, sursum contractis, summo apice obtusiusculis.

Matto Grosso: Santa Anna da Chapada in ora silvae in summis rupibus praeruptis (18 Sept. 1902; II. 2322). „Folia novella laete viridia. Petala interiora rubra" (Malme).

Diese schöne Art ist mit der Ab. Marcgraviana am nächsten und zwar sehr nahe verwandt; von dieser unterscheidet sie sich jedoch leicht durch oben glatte und glänzende Blätter und kürzere Blütenstiele, wie auch durch die dicht unter dem Kelche sitzende Braktee, spärlicher schülferige Kronenblätter etc.

2. Bocagea mattogrossensis R. E. Fries, l. c., IV, no. 19, p. 12, tab. 4 , fig. $1-4$.

Arbor ramulis rigidis, fuscis, puberulis et dense foliiferis; foliis coriaceis, breviter petiolatis, lanceolatis vel oblongo-lanceolatis, apice paulatim contractis, summo apice obtusiusculis, basi valde inaequali acutis, supra viridibus glaberrimis, subtus glaucis et novellis parcissime adpresse hilsutis, glabrescentibus; inflorescentiis paucifloris in ramulis decurtatis sitis; baccis globosis, glaberrimis.

Matto Grosso: Santa Anna da Chapada in silva (26 Sept. 1902; II. 2390).

Die Art steht der Bocagea multiflora Mart. am nächsten. Die Exemplare wurden mit einem Pöppigschen Typusexemplare dieser Art (vom Berliner Bot. Museum) wie auch mit von Riedel am Rio Negro gesammelten Exemplaren (vom Bot. Museum zu St. Petersburg) verglichen. Von diesen wichen sie durch die behaarten, steiferen, gröberen und dichter be- 
blätterten Sprosse $a b$. wie durch die grösseren und steiferen Blätter mit ausgeprägter schiefer Basis und allmählich verjüngter, nicht abgesetzter Spitze, durch spärlichblütigere Infloreszenzen usw. Indessen ist die sehr nahe Verwandtschaft mit $B$. multiflora offenbar.

3. Oxandra Riedeliana R. E. Fries, l. c., V, no. 4. p. 2, tab. II, fig. $7-9$.

Arbor parva, ramulis glabris, toliis basi acutissimis, apice longe acuminatis, summo apice obtusatis, glaberrimis, subtus sparse verruculosis; inflnrescentiis multifloris axillaribus vel ex axillis foliorum delapsorum erumpentibus: pedunculis ferrugineo-hirsutulis, basi ac medio bracteolatis; alabastris ovoideis, glabris: staminibus $11-16$; pistillis $2-4$.

Amazonas: In silvis humidis prope Borba (Aug. 1828; Riedel 1389).

Malmea nov. gen. R. E. Fries, 1. c., V. no. 4, p. 3, tab. I, fig $7-12$.

Flores actinomorphi, hermaphroditi. Sepala 3 , aestivatione imbricata. Petala 6, sepalis multo majora, libera, biseriata et subaequalia. rotundatoovalia, patentia, aestivatione omnium imbricata. Stamina numerosa, cuneata, connectivo supra loculos simplices extrorsos truncato-dilatato. Torus hemisphaerico-columnaeformis. Carpella numerosa, ovulo solitario, basali, stigmate clavato, sessili. Fructus (ignotus). - Arbor vel frutex foliis distichis, breviter petiolatis, integerrimis, penninerviis, floribus mediocribus, in cicinno oppositifolio sitis.

Die Pflanze, die der hier fraglichen Gattung zugrunde liegt, lag in der Riedelschen Sammlung unter den Guattarien, zusammen mit Guatteria p.silopus Mart., an welche sie auch bei flüchtiger Betrachtung habituell etwas erinnert. Von dieser Gattung wie von allen anderen AnonaceenGattungen unterscheidet sie sich jedoch durch solche Charaktere, dass sie mir den Rang einer besonderen Gattung zu verdienen scheint.

Als ein besonders wichtiges Merkmal sei die imbrikate Knospenlage sowohl des Kelches als aller Blätter der Blumenkrone hervorgehoben. Von amerikanischen Gattungen ist nur Oxandra durch dasselbe Verhältnis ausgezeichnet, von dieser aber unterscheidet sich unsere Art ausser durch die Grösse der Blüte, die Form der Blütenblätter usw. leicht und sehr scharf durch den Bau der Staubblätter mit dèm oberhalb der Pollensäcke ausgebreiteten Konnektivum. Die Malmea-Gattung steht auch in Wirklichkeit weit von Oxandra ab.

Nähere Verwandtschaft dürfte sie dagegen mit der malaiischen Gattung Griffithia haben, mit der sie in vielen Hinsichten nach Kings Beschreibung dieser Gattung übereinstimmt. Durch folgende Charaktere unterscheidet sie sich jedoch von derselben: die Blüten haben weit geringere Dimensionen und sitzen in einem den Blättern entgegengesetzten Wickel; die Kelchblätter decken einander tütenförmig in der Knospenlage (das erste die beiden inneren, das zweite das innerste), älter aber decken sich ihre Ränder nicht; die beiden Kränze der Blumenblätter sind einander ziemlich gleich, die inneren sind nicht kleiner und schmäler, nicht an der Basis dicker und ausgehöhlt. wie das bei Griffithia der Fall ist; die Blumenkrone ist bei der entfalteten Blüte ausgebreitet: die Narben sind ungestielt, 
keulenförmig. Mehrere dieser Charaktere sind von so grosser Bedeutung für die Abgrenzung der Gattungen innerhalb der Familie, dass es mir unmöglich erschienen ist, die Gattungen zu vereinigen, wogegen auch die geographische Verbreitung entschieden spricht.

In einer Reihe von Charakteren, in der Knospenlage der Kronenblätter, dem Bau der Staubfäden und Fruchtknoten mit einzelnen basalen Samenknospen usw., zeigt unsere Pflanze recht grosse Übereinstimmung mit den Gattungen Guatteria, Ephedranthus und Aberemoa. Abgesehen von der dachigen Knospenlage der Kelchblätter, ${ }^{1}$ ) die an und für sich es unmöglich macht, die Art zu einer der genannten zu stellen, sprechen indessen noch andere Sachen gegen eine solche Zusammenstellung. Die in einem Wickel angeordneten, mit zwei Vorblättern versehenen Blüten nebst dem den Blättern entgegengesetzten Platz der Infloreszenz sprechen gegen die Zuordnung der Pflanze zu einer der beiden erstgenannten Gattungen, während sie hierin mit der letztgenannten übereinstimmt. Von dieser unterscheidet sie sich jedoch gut durch die ungestielten Narben.

4. Malmea obovata R. E. Fries, 1. c., V, no. 4, p. 7.

Ramulis folijsque novellis pilis adpressis ferrugineis vestitis, mox glabrescentibus; foliis vetustioribus firmiter membranaceis, glaberrimis, subtus in nervo medio solum parcissime pilosis, obovatis vel obovatooblanceolatis, cuspidatis et summo apice obtusis, basi acutis; inflorescentiis oppositifoliis; floribus longe et graciliter pedunculatis; petalis glabris, margine solum ferrugineo-ciliatis.

Prov. Bahia: In silvis prope Castelnovo [Nov. 1821; Riedel 525]. "Arborescens; corolla aequalis, petalis viridibus, basi albis.“

5. Guatteria rigida $R$. E. Fries, l. c., V, no. 4, p. 8, tab. I, fig. 1-2.

Arbor; ramulis novellis parcissime strigillosis et mox glabrescentibus; foliis rigidis, obovato-ellipticis, basi cuneatis, apice obtusis, supra glaberrimis, subtus subtilissime strigillosis, glabrescentibus; pedunculis solitariis, glaberrimis, diametro floris brevioribus; sepalis acuminatis; petalis obovatis, apice rotundatis obtusisque, praesertim extus ad basim fulvo-sericeis.

Matto Grosso: In silvis umbrosis ad Rio Pardo [Aug. 1826; Riedel 438].

6. Unonopsis Riedeliana R. E. Fries, l. c., V, no. 4, p. 11, tab. II, fig. $1-6$.

Arbor; ramulis novellis, pedunculis et floribus extus dense fulvotomentosis; foliis breviter petiolatis, lineari-lanceolatis, basi acutis, in apicem longum sensim contractis, summo apice obtusiusculis, rigido-

1) Die Knospenlage der Kelchblätter der Gattung Ephedranthus ist freilich noch nicht mit voller Sicherheit bekannt; nach der Gattungsbeschreibung Spencer Moore's ist sie jedoch dachig. Vgl. hierüber Rob. E. Fries, Die Anonaceen der zweiten Regnell'schen Reise, pag. 6 (K. Sv. Vet.Akad:s Arkiv för Botanils. Bd. 4. N:o 19. 1905). 
membranaceis, novellis supra et subtus parcissime adpresse hirsutis et mox glabrescentibus, vetustioribus supra glaberrimis nitidisque, subtus crebre verruculosis et in nervo medio solum pilis adpressis rarissimis vestitis; floribus paucis v. numerosis in ramulis decurtatis sitis.

Brasilien ohne nähere Angabe des Fundortes [Riedel et Langsdorff]. Rio de Janeiro: Mandiocca in silvis [Oct. 1823; Riedel].

Die Art weicht von allen anderen Arten der Gattung durch die Form der Blätter ab; sie ist auch durch den Bau der Infloreszenzen, durch die gelbbraune Behaarung der Blütenstiele etc. gut charakterisiert.

7. Anona tomentosa R. E. Fries, l. c., V, no. 4, p. 18, tab. III, fig. 5-7.

Syn.: Anona crotonifolia [pro parte] Warming in Medd. Naturh. Foren. Kjöbenh. 1873, p. 157, et Rob. E. Fries, Beiträge, in K. Sv, Vet. Ak. Handl. XXXIV. n. 5. p. 44.

Frutex mediocris; ramulis, foliis supra et subtus, pedunculis, calyce et petalis exterioribus extus dense fulvo-tomentosis; foliis oblongis, ovatis vel ovalibus, basi rotundatis vel subcordatis, apice brevissime acutis, rotundatis vel interdum emarginatis; inflorescentiis 1-2-floris extraaxillaribus, ex internodiis erumpentibus; sepalis rotundatis, acuminatis; petalis omnibus subaequilongis, exterioribus quam interioribus duplo triplove latioribus.

Brasilia: S. Antonio do Monte [Sellow 1965; in herb. Berolin.; specimen foliis vetustioribus glabrioribus praeditum]. Minas Geraës: ohne nähere Angabe des Fundortes [1824; Riedel]; in campis siccis arenosis inter Paracatú et Rio S. Francisco [Sept. 1834; Riedel 2648]: Lagoa Santa in campis siccis [Oct. 1824; Ricdel 736]; ibid. [1864; Warming 744]; Caldas (?) [Regnell III. 251; in herb. Upsal.]. Sao Paulo: in campis Ytú, Sorocaba et S. Carlos [Febr.-Mart. 1834; Riedel]: S. Simao in cerrado [19 Nov. 1889; Commissao Geographica e Geologica da Prov. S. Paulo no. 267; in herb. Hauniensi].

Anona tomentosa unterscheidet sich sehr deutlich von crotonifolia, u. a. hauptsächlich durch folgende Merkmale. Sie ist ein höherer, verzweigter Strauch; die Blätter sind an der Basis stets abgerundet oder eingebuchtet; die Blüten sitzen in 1-2-blütigen Infloreszenzen zwischen den Nodi, nicht endständig oder blattgegenständig; die Kelchblätter sind kürzer und breiter und sind mit einer abgesetzten, scharfen Spitze versehen. Tatsächlich scheinen die zwei Arten nur wenig verwandt zu sein; Anona tomentosa steht der Malmeana viel näher, was besonders in den Infloreszenzen und in der Form sowohl der Laubblätter als der Kronenblätter hervortritt. Von dieser weicht jedoch $A$. tomentosa u. a. durch die auch oben dicht filzhaarigen Blätter ab. 